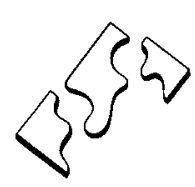

162

\title{
Piaget and the Egocentric Tradition
}

\author{
Wilfred H. O. Schmidt \\ University of Alberta
}

Yet an adult demonstrates his egocentrism through his conviction that all mental development must naturally and inevitably lead to modes of thought and feeling exactly like his own, bearing, moreover, the particular stamp of the time and place in which he lives. (Henri Wallon, 1973a)

The reason why Piaget's developmental psychology has had such a fascination for educators and psychologists is, in part, that it appears to be based on good empirical data collected in ingenious experiments or in semi-natural settings. For teachers there is the additional bonus that in those experiments Piaget addresses topics that are familiar to them from their own classroom experience.

However, Piaget provides not only empirical data. He also supplies concepts to interpret the data: central concepts such as egocentricity, subject and object, action, interaction, adaptation, equilibrium, structure, and transformation. Such concepts are theory-laden. They go far beyond the information given in the empirical data. They have their origins in particular contexts of inquiry, and their extension to other contexts of human endeavour are always fraught with the possibility of distortion and misunderstanding. Piaget himself has warned his readers that his theory of development, which is mainly a theory of development of cognitive functions, "is impossible to understand if one does not begin by analyzing in detail the biological presuppositions from which it stems and the epistemological consequences in which it ends," (quoted in Boden, 1980). This warning clearly deserves to be taken seriously. The fact that this has not always been done has led to the spectacle in North American psychology which Broughton, in the first of five essays devoted to a comprehensive critique of Piagetian theory, describes as follows:

The structure of Piaget's theory has been dismantled in the rush to appropriate particular empirical techniques, replicate specific studies, develop test items or curricular materials, and produce piecemeal critiques. The whole conception of "genetic epistemology" has been laid waste by bevies of hyperkinetic researchers who resemble nothing more than ardent rummagers in a bargain basement. (1981)

In what follows we shall take one central concept in Piaget's account of child development, viz. the concept of egocentricity, and examine its relation to the epistemological questions from which it arises. "Egocentricity" brought Piaget to immediate prominence amongst psychologists and educators when he published his first book in the field of psychology: Language and Thought of the Child (1923). Piaget himself continued to attach importance to this concept as his systematic theory of stages of cognitive development was articulated.

Language and Thought of the Child contains a Preface by Claparede, director of the Institute J. J. Rousseau, and a Foreword by Piaget who at the time of publication of the book had been a member of the Institute for two years. From the Preface and the Foreword we get a good indication of what one might call the intellectual landscape within which Piaget develops his inquiries into language and thought.

Claparede states the aims of the Institute J. J. Rousseau as being the scientific study of the child and the training of teachers. What is meant by 
"scientific" in this context can only be inferred from statements he makes concerning the special merit of the research on which Piaget has reported. We read that "what strikes one in this first book of his is the natural way in which the general ideas have been suggested by the facts; the latter have not been forced to fit ready-made hypotheses." A little further on Claparede claims that Piaget's familiarity with logic and epistemology "has enabled him to draw the line very clearly between psychology and philosophy, and to remain rigorously on the side of the first. His work is purely scientific" (emphasis added). In orienting the reader to the significance of Piaget's contribution, Claparede also refers to seminal ideas in biology.

In an attempt to cast more light on the disciplines so far mentioned and on their possible role in Piaget's thinking when he wrote Language and Thought of the Child, Claparede's Preface and Piaget's Foreword will be taken together as if they were one.

\section{Psychology}

Claparede mentions Freud's distinction between "the plane of subjectivity" (pleasure principle, autistic and symbolic thinking), that is said to dominate the child in the first few years of life, and "the plane of objectivity, speech and logical ideas," which "is built up little by little by social environment" (reality principle, logical thinking). Then mention is made of the "clinical method," which Piaget links to the name of Janet and describes as the art of questioning as practised by psychiatrists and which makes possible a focus on qualitative rather than quantitative changes in the course of development. Piaget also adds the name of J. M. Baldwin who, like himself, was deeply influenced by evolutionary theory. Finally, reference is made to "functionalism" of which Claparede was a proponent.

\section{Biology}

Claparede mentions biology mainly to show the continuity in Piaget's scientific method from his earlier biological research to his research into the language and thought of the child. In his biological research Piaget had collected data that would throw light on the relation between the shapes of molluscs and the altitude in which they live in the Valaisian Alps - this being a special case of the relation between variation and adaptation. The continuity in scientific procedure is seen in the careful collecting, recording, and cataloguing of the observations in order "to see the assembled materials in a clearer light, to facilitate the task of comparing and affiliating one to the other." Piaget himself mentions biology only in pointing to future plans: "I hope in a few years' time to produce a work dealing with child thought as a whole, in which I shall again take up the principal features of child logic, and state their relation to the biological factors of adaptation (imitation and assimilation)."

\section{Logic and Epistemology}

While Claparede is not very specific here, assuring us only that "Piaget is among the best informed on all philosophical questions. . . he shares the 
hope of the new logic, and is acquainted with the delicate problems of epistemology," Piaget himself says much more about these areas of inquiry. He mentions names and book titles and makes comments, which clearly indicate that at that time he already had a vision of links between the evolution of scientific and mathematical thought and the cognitive development of the child. However, he is acutely aware of "the risk of succumbing to preconceived ideas, to the easy analogies suggested by the history of science and the psychology of primitive peoples, or worse still to the prejudices of the logical or epistemological system to which we unwittingly subscribe, try though we may to maintain a purely psychological attitude of mind." He wishes the essays contained in the book, therefore, to be regarded "first and foremost [as] a collection of facts and documents," and he claims that he has confined himself "strictly to the discussion of facts," though only "for the time being" (emphasis added).

Now let us look at the "collection of facts and documents" provided by Piaget. The book reports on five separate studies which Piaget always refers to as "studies in child logic," even though the empirical data always consist of speech samples. We shall analyze only the first study, entitled "The functions of language in two children of six," for it is in this study that Piaget introduces the concept of egocentrism for the first time.

The data collected consist of a record of everything that two six-yearold boys, observed by two separate observers, said in the course of a month at the Maison de Petits l'Institut Rousseau, together with a record of the contexts in which it was said. The talk was then portioned out in numbered sentences, and these were examined to find "elementary functional categories" into which they could be classified. To demonstrate the process, Piaget presents one extract, consisting of sentences numbered 23 to 37 , together with the elementary functional categories that suggested themselves to him.

The first category that is identified is "monologue." Piaget illustrates this with examples of speech produced by one boy whose bosom friend is sharing the same table with him and is busy drawing, as he is. Piaget comments that "it would therefore be natural in a case of this kind if the sole function of speech were to communicate thought." "Natural?" today's reader may ask. Would it not be more natural to assume that bosom friends, enjoying each other's company while each is also absorbed in his own drawing activity (not engaged in a joint problem solving task), would not use language solely to communicate thought? Whether we agree with Piaget's assumption or not, he tells us that the boy is obviously not communicating thought: "he is thinking aloud over his own drawing," and adds: "just as people of the working classes mutter to themselves over their own work" (Why working classes?). Piaget quotes further utterances from the same boy to show that the boy "cares very little who is listening to him" nor, when he does address a person, "whether the person he addresses has really heard him or not."

The second category that suggests itself to him is "collective monologue." This is exempified by the two children talking to each other but without attending to the content of what the other has said. 
The third category Piaget names "adapted information": "In this case the child talks, not at random, but to specified persons, and with the object of making them listen and understand." An example in Piaget's records is the boy going up to the teacher and saying "Please, teacher, Ez hasn't finished," or a boy looking at a picture together with another child saying, "But the trams that are hooked on behind don't have any flags."

Further categories into which speech samples are grouped include: "criticism," commands, requests, and threats, and "questions," answers, senseless repetitions (echolalia). Piaget calls these categories which the data have suggested to him the "elementary functional categories," and he immediately proceeds to divide them into two groups. The one he labels "egocentric," the other "socialized." Monologue, collective monologue, and senseless repetitions fall under the rubric of egocentric. Adapted information, criticism, commands, requests, threats, questions (with some exceptions), and answers fall under the rubric of socialized.

We shall now focus our attention on the notion of egocentricity and follow Piaget's own clarification of the concept from the early beginning, in 1923, when a whole series of "studies in child logic" were still part of his plans for the future, to his much later statements when his theory of cognitive development had been fully elaborated and the relation between child logic and biological factors had been specified. To do this adequately, we have to first turn to philosophy, then biology, and genetic epistemology in order to examine the tradition in which Piaget's questioning originates.

We start with philosophy. There are empiricist and rationalist views of how knowledge is acquired or constituted. The empiricist view is usually traced back to Locke's notion of the mind starting as tabula rasa, all knowledge being seen as coming from the senses and from "outside." The question then is how the sense impressions come to be organized "to make sense" and how abstract ideas come to be formed. Laws of association are then invoked as explanatory principles in both philosophy and psychology. Historically, the discussion was first in terms of sensation, perception, and the association of ideas-with behaviorism in psychology the emphasis shifted to the association between stimuli and responses.

Piaget rejects the empiricist account of how knowledge is acquired on the grounds that it leads both to a view of acquisition of knowledge as a passive and merely additive process and to a view of science as an inductive accumulation of facts. The empiricist, according to Piaget, is quite rightly concerned with experience, but he cannot explain the forms or structures of knowledge and of thought. When Piaget speaks of the cognitive development of the child, he speaks, as is well known, of the development of cognitive structures.

The rationalist view is usually traced back to Descartes, who argues that we can never trust our senses and that the only certainty that we have rests on the indisputable fact that we think: "I think, therefore I am."

As John Macmurray (1956) has pointed out, for Descartes the statement was equivalent to "I am a substance whose essence is thinking," and its significance in terms of the time in which Descartes lived was that it 
was a challenge to authority. Macmurray paraphrases the statement as follows: "I am a thinking being: to think is my essential nature. I have therefore both the right and the duty to think for myself, and to refuse to accept any authority other than my own reason as a guarantor of truth."

But for a theory of how knowledge is acquired, we are left with what seems an unbridgeable gulf between what comes through the senses and what originates in the rational activity of the mind. We have a dualism of body (sense impressions) and mind (rationality, innate ideas).

Piaget is closer to rationalism than to empiricism. When Piaget speaks of the rationalist position, he refers specifically to Kant, the eighteenth century philosopher, because Kant addresses himself to the issue of how the gulf between sense impressions and rationality can be bridged. According to Kant, the sense impressions or, to use Kant's terms, our intuitions and perceptions would remain meaningless if we did not have forms of sensibility and categories of thought that rendered them intelligible to us. The forms of sensibility are space and time. The categories are purely logical: categories of quantity, of quality, of relation (e.g., cause and effect, reciprocity), and of modality (e.g., necessity and chance, possibility and impossibility). Kant calls the forms of sensibility and the logical categories a priori conditions for constituting knowledge, which means simply that without them no knowledge would be possible. Without intuitions and perceptions the purely logical categories are "empty"; without the purely logical categories the intuitions and perceptions are "blind." The categories and the intuitions exist, so to say, in their mutuality, and it is in their mutuality that the world which is sensed by us becomes intelligible.

What attracts Piaget to Kant is the latter's concern with logical structures. However, he cannot accept Kant's apriorism, which makes it seem that the categories of thought are innate or pre-formed. Piaget wants to know what is the origin and genesis of the logical structures that we identify in the advanced thinking of the scientist and the mathematician. As a biologist used to thinking in terms of organisms, interaction between organism and environment and adaptation processes (assimilation and accommodation), continuity of function across species from the most lowly to the most advanced together with the genesis of new structures and even new species, he sees advanced logical structures in principle as serving also a biological function and having their origin in earlier structures of the acting organism. In this respect too Piaget stands in a tradition. He had his forebears in Herbert Spencer, the philosopher, and James Mark Baldwin, the psychologist. Both Spencer and Baldwin placed the human being in an evolutionary context and sought to understand the emergence of "mind," of intellectual functioning, of social behaviour, and of morality from within this context. Terms that are crucial in Piaget's own theorizing already occur in Spencer (the adaptive function of intelligence, equilibrium, and equilibration) and in Baldwin (assimilation, imitation, and schema). The latter also coined the term genetic epistemology. However, neither Spencer nor Baldwin (even though he had founded a laboratory for experimental psychology at the University of Toronto) provided much empirical data to support his theory. Piaget, by contrast, has been a prolific generator of observational data on children of all ages. In 
summary, we can say that Piaget comes to the observation of children's behaviour with an epistemological question traditionally dealt with in philosophy, he has a conceptual framework to deal with the question that arises from biology, and in the process of answering the question, he becomes a psychologist studying the cognitive development of children. It may be interesting at this point to add that the publications of Piaget for several decades were mainly in psychology.

In 1923, Piaget's focus was on egocentric speech. The meaning he gives to the term "egocentric" is captured in the following statements about the samples of speech utterances of the two boys observed:

\footnotetext{
The talk is egocentric,... chiefly because he does not attempt to place himself at the point of view of the hearer (p. 9, emphasis added). Throughout the time when he is learning to speak, the child is constantly the victim of a confusion between his own point of view and that of other people (1923, p.17, emphasis
added).
}

But Piaget's real interest is in logical thought. The relation of speech to thought is then clarified by referring to Freud's distinction between directed or intelligent thought and undirected or "autistic" thought. Autistic thought creates for itself a dream world of imagination; it is not adapted to reality; it tends to "satisfy desires, not establish truths"; it is "strictly individual and incommunicable as such by means of language." Directed or intelligent thought is "adapted to reality"; it "admits of being true or false"; it "can be communicated by language." He defines egocentric thought now as an intermediate form between autistic and intelligent thought: "it seeks to adapt itself to reality, but does not communicate itself as such."

In 1959, in the third edition of Language and Thought, Piaget responds to his critics by formulating his position at that stage. He no longer regards the distinctions taken from Freud as necessary to his explanation of egocentrism. He still defines egocentrism as "an inability to differentiate between one's own point of view and other people's" but adds the inability to differentiate "between one's own activity and changes in the object" (emphasis added). This addition is significant because it marks a shift away from the earlier use of communicability of thought (through language), as a criterion for identifying thought on a continuum from autistic to directed, to the postulated origins of structures of thought in sensori-motor actions. What previously had been called autistic thought now becomes a radical egocentrism. This radical egocentrism is an intellectual one and consists of the complete inability to distinguish between the knowing subject and the known object. Piaget's explanation of how the distinction first comes to be made relies on his observations of the sensori-motor actions and coordinations of his own three children in their first two years of life. This is not the place to enter into the details. It is sufficient to remind the reader that Piaget believes that at first objects are experienced by the infant as simply extensions of action, that Piaget's detailed analysis of six substages of sensori-motor development is supposed to show how objects are gradually differentiated from individual actions and begin to be seen as independent of action and having "permanence," and that imitation of actions of others (such as tongue protrusion) is supposed to be impossible until the infant has imitated 
(repeated) its own actions in order "to make interesting spectacles last." The radical egocentrism is thus reduced, but egocentrism still manifests itself in different forms in the course of the individual's development through the preoperational stage, the concrete operational stage, to the formal operational stage.

The ideal end-state of cognitive development is the attainment of formal operational thinking as exemplified in logic and mathematics, which seems to transcend "the limitations contingent upon our spatiotemporal embodiment" (Boden, 1980): in other words, when the individual has moved beyond individual (egocentric) perspectives by coordinating all possible perspectives. (This, I take it, is the target of Merleau-Ponty's statement that Piaget's theory puts itself at the point of view of God himself.) Piaget makes the distinction between the individual subject (still very much influenced by the constraints of his spatiotemporal embodiment_carried away by subjective impressions, physical action, and perceptual immediacy) and the epistemological subject (thinking flexible, reversible, and governed by logical necessity). The subject referred to by Piaget is, in fact, a reified subject, the Subject as Thinker, not the full-bodied human being in his concrete sociocultural historicity and in his lifeworld. Piaget makes scathing comments about people who characterize the subject in terms of "lived experience," and points out that:

if, then, to account for the construction (i.e., of cognitive structures). . we must appeal to the subject's acts, the subject here meant can only be the epistemic subject, that is, the mechanism common to all subjects at a certain level, those of the "average" subject. (1970, p. 68)

In this connection it is important to note that, although Piaget introduced the "clinical method" to study children's ways of thinking, he is "not like the true clinician, interested in this or that individual person" (Boden, 1980).

The philosophical tradition which we have identified as the one in which Piaget stands is described and critiqued by John Macmurray in his Gifford Lectures $(1956,1961)$. Macmurray speaks as a philosopher, and he is not addressing himself to psychologists in particular nor does he mention Piaget's theory. What is interesting is that he speaks at length about philosophers in this tradition "who are imprisoned in an egocentric predicament" and "who discuss with one another how any of them can know that the others exist, and find no satisfactory solution. We are so used to this that we no longer notice how comical it is." The notion of egocentricity can, in fact, be regarded as part and parcel of this particular tradition in philosophy because "any philosophy which takes its stand on the primacy of thought, which defines the Self as Thinker, is committed formally to an extreme logical individualism. It is necessarily egocentric." It should come as no surprise to us then that Piaget, who studies children in order to answer epistemological questions, should continue the debate of philosophers on how any of them can know that the others exist (or that anything exists objectively) by positing that at the beginning of life no one knows this (radical egocentrism). What is different in Piaget is how he seeks the answer and the answer that he proposes. 
How he seeks the answer is well known, but a few comments are in order. Piaget has always stressed the need for more qualitatively than quantitatively oriented research. He has been a critic of psychometric approaches to the study of intelligence, and in his own research quantification has played a very subsidiary role. He has consistently rejected positivism, whether of the logical or the empiricist variety. Though he asks questions which come from a philosophical tradition, he is disillusioned with philosophy and most of all with "philosophical psychology." He is dismayed with the existential-phenomenological writing of Merleau-Ponty and Sartre, but he speaks with respect of the aims of Husserl's method of phenomenological reduction, and he even sees a

convergence between that which the psychology of intelligence studies under the name of 'operational structures' and that which Husserl's phenomenology seeks to reach below the level of empirical or spatio-temporal consciousness. (1972, p. 109)

However, Piaget puts more faith in observation and experiment, and he regards the biggest shortcoming of phenomenology "its neglect of historical and genetic points of view." In this respect his criticism of Husserl is similar to that of his criticism of Kant. It is important to note that when Piaget here speaks of the historical point of view, he is not speaking of the individual's embeddedness in a sociocultural community with a history, but only of the history of the transformations of the cognitive structures in the individual. This becomes clear when we see that Piaget has no patience with the notion of a lived world (Lebenswelt), which began to play an important role in Husserl's later years and which implies a shared, historically developed sociocultural world into which we are born.

The question to be asked at this point is: must we, if we want to understand the cognitive development of children (and not some other aspect of development), start with Piaget's philosophical assumptions to guide our observations and experiments? Clearly not. Piaget's earliest critics, who also were good observers and experimenters, already suggested alternatives. Henri Wallon in France (1973), William Stern in Germany (1967), Vygotsky in Russia (1962), and Susan Isaacs in England (1930) all paid much more attention to the child as a social being and hence to the interpersonal, social, and cultural matrix in which all development, including intellectual development, must be seen. Somewhat later Heinz Werner and Bernard Kaplan in Symbol Formation (1963) spoke of the "primordial sharing situation" between mother and child which precedes the communicating of messages to the other, and they have argued that the act of reference emerges not as an individual act but as a social one: "by exchanging things with the other, by touching things and looking at them together."

Very recently there has again been a flurry of very careful experimental research which still tries to answer the question, "Are young children egocentric?" (Cox, 1980). Even though the researchers are coming to conclusions very different from those of Piaget, they are still reluctant to discard the term egocentric from their vocabulary.

There is also a great deal of empirical research into the social origins of symbolic functioning, which, while recognizing the value of many of Piaget's empirical observations, rejects Piaget's philosophical 
presuppositions. David Smillie's paper "Rethinking Piaget's Theory of Infancy" (1982) deals with some of this research taking place in England and North America (see e.g., Lock, 1978). When these researchers refer to a philosophical grounding for their ideas, they increasingly refer to the British philosopher John Macmurray, who proposes an alternative to the "Subject as Thinker." This alternative is encapsulated in the titles of the two books that formed the substance of his Gifford Lectures delivered in 1953-54: The Self as Agent (1956) and Persons in Relation (1961). It is interesting to note that the American psychologist Hans Furth, whose work has been strongly in the Piagetian tradition, recently published a paper (1982) drawing the attention of developmental psychologists to the philosophy of Macmurray.

Macmurray has two basic propositions:

The Self must be conceived, not theoretically as subject, but practically as agent. . .human behaviour is comprehensible only in terms of a dynamic social reference. (1956, p. 38)

For Macmurray it is important to stress that the infant is, from the very beginning, not just an individual organism (though "the organic" enters into all human behaviour) but a person in relation to another person. Persons, he says, "are constituted by their mutual relation to each other. ' $\mathrm{I}$ ' exist only as one element in the complex 'You' and 'I'." And he looks at the relation between infant and mother in order to show that "human behaviour carries always, in its inherent structure, a reference to the personal Other" (1961, p. 61). It is consistent with such a philosophical reorientation that in empirical research the notion of a radical egocentricity at birth is being replaced by the concept of primary intersubjectivity (Trevarthen, 1977).

\section{References}

Boden, M. A. (1980). Jean Piaget. New York: The Viking Press.

Broughton, J. M. (1981). Piaget's Structural Developmental Psychology I. Piaget and Structuralism. Human Development, 24, 78-109.

Cox, M. V. (Ed.) (1980). Are Young Children Egocentric? London: Batsford Academic and Educational Ltd.

Furth, H. (1982). John Macmurray's Philosophy of the Form of the Personal. Human Development, 25, 365-372.

Isaacs, S. (1930). Intellectual Growth in Young Children. London: Routledge.

Lock, A. (Ed.) (1978). Action, Gesture, and Symbol. London: Academic University Press.

Macmurray, J. (1956). The Self as Agent. London: Faber and Faber.

Macmurray, J. (1961). Persons in Relation. London: Faber and Faber.

Piaget, J. (1959). The Language and Thought of the Child. (3rd ed.) London: Routledge and Kegan Paul. (Original work published 1923).

Piaget, J. (1952). Play, Dreams, and Imitation in Childhood. (C. Gattegno \& F. M. Hodgeson, Trans.). New York: W. W. Norton. (Original work published in 1946).

Piaget, J. (1953). The Origins of Intelligence in the Child. (M. Cook, Trans.) New York: International University Press. (Original work published in 1936).

Piaget, J. (1954). The Child's Construction of Reality. (M. Cook, Trans.) New York: Basic Books. (Original work published in 1936). 
Piaget, J. (1970). Structuralism. (Chaninah, Trans.) New York: Basic Books. (Original work published in 1968).

Piaget, J.(1972). Insights and Illusions of Philosophy. (W. Mays, Trans.) London: Routledge and Kegan Paul. (Original work published in 1965).

Piaget, J. (1971). Genetic Epistemology. (E. Duckworth, Trans.) New York: Columbia University Press. (Original work published in 1970).

Smillie, D. (1982). Rethinking Piaget's Theory of Infancy. Human Development, 25, 282-294.

Stern, W. (1967). Psychologie der Fruhen Kindheit. (9th ed.) Heidelberg: Quelle und Meyer.

Trevarthen, C. (1977). Communication and Cooperation in Early Infancy: A Description of Primary Intersubjectivity. In M. Bullowa (Ed.) Before Speech: The Beginnings of Human Cooperation. Cambridge: Cambridge University Press.

Vygotsky, L. S. (1962). Language and Thought. Cambridge, MA: M. I. T. Press.

Wallon, H. (1973a). The Psychological Development of the Child. International Journal of Mental Health, 1,(4), 29-39.

Wallon, H. (1973b). The Emotions. International Journal of Mental Health, 1,(4), 4052.

Wallon, H. (1973c) The Origins of Thought in the Child. International Journal of Mental Health, 1,(4), 53-66.

Werner, H., \& Kaplan, B., (1963). Symbol Formation. New York: John Wiley and Sons. 